\title{
Comparison of maternal health services and indicators in three districts of the Vol- ta Region, Ghana
}

\author{
Eun Woo Nam ${ }^{1}$, Afisah Zakariah ${ }^{2}$, Festus Adams ${ }^{2}$, Young Suk Jun ${ }^{3}$ and Richard Adanu ${ }^{4}$ \\ Ghana Med J 2016; 50(3): 122-128 DOI: http://dx.doi.org/10.4314/gmj.v50i3.2
}

${ }^{1}$ Department of Health Administration, College of Health Sciences and Yonsei Global Health Center, Yonsei University Wonju, Republic of Korea ${ }^{2}$ Policy, Planning, Monitoring \& Evaluation(PPME) Directorate, Ministry of Health, Accra, Ghana ${ }^{3}$ West Africa Team, Korea International Cooperation Agency, Republic of Korea ${ }^{4}$ University of Ghana School of Public Health, Legon, Accra

Corresponding author: Professor Richard M. Adanu $\quad$ E-mail: rmadanu@ug.edu.gh

Conflict of interest: None declared

\section{SUMMARY}

Background: Ghana's maternal mortality ratio continues to decline, but is not expected to meet the Millennium Development Goal (MDG) 5 target. The Ghana Health Service and Ministry of Health have displayed a high commitment to the improvement of maternal health in the country. One of the most recent partnerships directed at this is with the Korea International Cooperation Agency.

Methods: This study was conducted among women between ages 15 and 49 resident in Keta Municipal, Ketu North and Ketu South districts in the Volta Region of Ghana who were pregnant or who had children aged less than five. Ethical approval was obtained from the Ghana Health Service Ethical Review Committee. Data were collected using questionnaires, entered into Stata version 12 and analyzed using frequency distribution and assessment of means. Comparisons among districts were conducted using chi square test and one way analysis of variance (ANOVA).

Results: The study covered 630 women whose mean age was 28.4 years. Almost all participants (99.1\%) from Ketu North knew where to obtain family planning services. Use of modern contraception was highest in Ketu North with $31 \%$ of respondents using a modern method. Delivery in a health facility was highest in Keta Municipal $(62.3 \%)$ with overall institutional delivery being $57.6 \%$. Delivery by a skilled birth attendant (SBA) was also highest in Keta Municipal.

Conclusion: Indicators used to assess maternal health services show a coverage of over $50 \%$ but we need to improve institutional delivery, use of modern contraception and education about danger signs in pregnancy.

Funding: This work was supported by the National Research Foundation of Korea Grant funded by the Korean Government (NRF-2013S1A5B8A01055336) and the Korea International Cooperation Agency(2013).

Keywords: Maternal Health, Ghana, Volta Region, Family Planning, Skilled Birth Attendant

\section{INTRODUCTION}

The maternal health indicators for Ghana are one of the best in the West African sub-region. ${ }^{1}$ Despite this, the estimated maternal mortality ratio (MMR) of 350 per 100,000 live births is very high, ${ }^{1}$ Although Ghana's MMR continues to decline, it is not expected that Ghana will achieve the Millennium Development Goal (MDG) 5 target. The Ghana Health Service and Ministry of Health have displayed a very high commitment to the improvement of maternal health in the country.
One of the most recent partnerships directed at this is with the Korea International Cooperation Agency (KOICA). ${ }^{2}$ In Ghana there are health posts, health centers, district and regional hospitals which provide maternal health care. ${ }^{3}$ The Ministry of Health is partnering with KOICA to address maternal health in the Volta Region of Ghana. The Volta Region is one of the regions in the country with the poorest maternal health indicators. The proportion of births covered by skilled birth attendants (SBA) in the Volta Region is $64.0 \%{ }^{4}$ while the national average is $68.4 \%{ }^{4}$ 
The 2010 national census also gives a pregnancy associated mortality rate for the Volta Region to be 706 per 100,000 live births..$^{5}$ This figure is actually higher than the MMR for the region since it includes deaths which are not maternal deaths.

The Ministry of Health has asked KOICA to work in the Keta Municipal, Ketu North and Ketu South districts of the Volta Region to plan interventions to improve maternal health. In order to design appropriate interventions, the team conducted a baseline assessment in the three districts. The aim of the study was to assess the state of maternal health in these districts and identify possible reasons for any differences in maternal health among the districts. The findings of the study will inform interventions by the Korea International Cooperation Agency program in Volta Region.

\section{METHODS}

\section{Study participants and data collection}

The study was conducted among women between ages 15 and 49 who were resident in Keta Municipal, Ketu North and Ketu South districts in the Volta Region of Ghana who were pregnant or who had children aged less than five. Data were collected through structured questionnaires between April 8-17, 2013, and a total of 630 questionnaires were distributed.

For the survey, "30x7" cluster sampling of WHO EPI was used. ${ }^{6}$ Clusters were selected within the districts using Enumeration Areas (EAs) developed for the Ghana Population and Housing Census in 2010. An EA is defined as an urban area or a village, a part of a village in a farming region or "a local society cluster" belonging to a group of villages. An EA has about 200 households. Regarding"30x7," 30 EAs are randomly picked from all EA lists within the district and seven households are picked for every EA. The EAs were picked through probability sampling. The sample size of each district is therefore 210 households. This resulted in a total of 630 households for the three districts.

Enumeration Area maps for each selected EA were created by the Ghana Statistical Service and those maps were used to confirm the division of EAs. In choosing the households to be studied, the modified random walk method was used in each EA. To avoid unnecessary duplication and improve sample distribution, once a household was selected, the most appropriate household member served as the respondent for the survey. Appropriateness was determined by a household member's reported knowledge of health and demographic issues relating to the household.
Other household members present were allowed to supplement answers from the household representative.

Seven trained research assistants in the three districts between April 8th and 17th, 2013 performed the data collection.

\section{Study tools}

The research team developed the questionnaires for the study. The finalization of the questionnaire design was done in collaboration with staff of the Ghana Health Service (GHS). Questionnaires were designed to include elements such as socio-demographic features, economic conditions, knowledge of nutrition, health and diseases, attitudes towards sex and family, use of family planning, pregnancy, labour and delivery experiences, newborn and child health, environmental health conditions and health care service needs.

\section{Analysis \\ Data collected were entered into Stata version 12 and analyzed using frequency distributionand assessment of means for continuous variables. Comparisons among the three districts were conducted using chi square tests for categorical variables and one way analysis of vari- ance (ANOVA) for continuous variables. A p value of less than 0.05 was considered to be significant}

\section{Ethical Approval}

This study was commissioned by the Ghana Ministry of Health in collaboration with Korea International Cooperation Agency (KOICA) both having the Ghana Health Service Research and Development Division and Yonsei University acting on their respective behalf. Ethical approval was obtained from the Ghana Health Service Ethical Review Committee on the $27^{\text {th }}$ of March 2013 with ethical clearance identification number GHS-ERC: 11/01/13.

\section{RESULTS}

The study covered 630 women from Keta Municipal, Ketu North and Ketu South in the Volta Region. There were 210 women from each locality whose ages ranged from 16 to 49 years with a mean age of 28.4 years ( $\mathrm{sd}$. 7.0). The mean age for each of the three districts is shown in Table 1. There was no statistical difference in the ages. Table 1 also shows the background characteristics for all the study participants by district. The significant differences in the background characteristics were with regard to occupation, marital status, and number of previous pregnancies and source of income. Women in Ketu South had a higher number of previous pregnancies and had a significantly lower proportion of married women. 
There were more farmers and housewives in Ketu North and a significantly higher proportion of people who had agricultural work serving as a source of income.

Table 1 Demographic characteristics of study participants from Keta Municipal, Ketu North and Ketu South in the Volta Region, Ghana

\begin{tabular}{|c|c|c|c|c|c|}
\hline Item & $\begin{array}{l}\text { Keta Munic- } \\
\text { ipal } \mathbf{N}=\mathbf{2 1 0}\end{array}$ & Ketu North $\mathbf{N}=\mathbf{2 1 0}$ & Ketu South N=210 & $\begin{array}{l}\text { Total } \\
\mathbf{N}=630\end{array}$ & p value \\
\hline Mean Age (sd) & $28.2(7.0)$ & $27.8(6.8)$ & $29.3(7.0)$ & $28.4(7.0)$ & 0.070 \\
\hline Average household size & 5 & 5 & 5 & 5 & 0.210 \\
\hline \multicolumn{6}{|l|}{ Religion } \\
\hline Christian & $139(66.2 \%)$ & $144(68.6 \%)$ & $125(59.5 \%)$ & $408(64.8 \%)$ & \multirow[t]{4}{*}{0.110} \\
\hline No religion & $28(13.3 \%)$ & $23(11.0 \%)$ & $32(15.2 \%)$ & $83(13.2 \%)$ & \\
\hline Moslem & $0(0.0 \%)$ & $1(0.5 \%)$ & $5(2.4 \%)$ & $6(1.0 \%)$ & \\
\hline Traditional & $43(20.5 \%)$ & $42(20.0 \%)$ & $48(22.9 \%)$ & $133(21.1 \%)$ & \\
\hline \multicolumn{6}{|l|}{ Occupation } \\
\hline Trader & $85(40.5 \%)$ & $84(40.0 \%)$ & $93(44.3 \%)$ & $262(41.6 \%)$ & \multirow[t]{7}{*}{$<0.001$} \\
\hline Unemployed & $45(21.4 \%)$ & $22(10.5 \%)$ & $53(25.2 \%)$ & $120(19.1 \%)$ & \\
\hline Artisan & $43(20.5 \%)$ & $28(13.3 \%)$ & $40(19.1 \%)$ & $111(17.6 \%)$ & \\
\hline Farmer/ Fisherman & $18(8.6 \%)$ & $45(21.4 \%)$ & $20(9.5 \%)$ & $83(13.2 \%)$ & \\
\hline Housewife & $7(3.3 \%)$ & $22(10.5 \%)$ & $0(0.0 \%)$ & $29(4.6 \%)$ & \\
\hline Student & $9(4.3 \%)$ & $5(2.4 \%)$ & $1(0.5 \%)$ & $15(2.4 \%)$ & \\
\hline Government worker & $3(1.4 \%)$ & $4(1.9 \%)$ & $3(1.4 \%)$ & $10(1.6 \%)$ & \\
\hline \multicolumn{6}{|l|}{ Highest educational level } \\
\hline No education & $37(17.6 \%)$ & $35(16.7 \%)$ & $52(24.8 \%)$ & $124(19.7 \%)$ & \multirow[t]{5}{*}{0.183} \\
\hline Primary & $62(29.5 \%)$ & $75(35.7 \%)$ & $68(32.4 \%)$ & $205(32.5 \%)$ & \\
\hline Middle/JHS & $92(43.8 \%)$ & $85(40.5 \%)$ & $77(36.6 \%)$ & $254(40.3 \%)$ & \\
\hline Secondary/SHS & $17(8.1 \%)$ & $10(4.8 \%)$ & $11(5.2 \%)$ & $38(6.1 \%)$ & \\
\hline Tertiary & $2(1.0 \%)$ & $5(2.3 \%)$ & $2(1.0 \%)$ & $9(1.4 \%)$ & \\
\hline \multicolumn{6}{|l|}{ Ethnicity } \\
\hline Ewe & $208(99.0 \%)$ & $209(99.5 \%)$ & $203(96.7 \%)$ & $620(98.4 \%)$ & \multirow[t]{3}{*}{0.027} \\
\hline Akan & $2(1.0 \%)$ & $0(0.0 \%)$ & $1(0.5 \%)$ & $3(0.5 \%)$ & \\
\hline Other & $0(0.0 \%)$ & $1(0.5 \%)$ & $6(2.9 \%)$ & $7(1.1 \%)$ & \\
\hline \multicolumn{6}{|l|}{ Marital status } \\
\hline Married & $198(94.3 \%)$ & $202(96.2 \%)$ & $205(97.6 \%)$ & $605(96.0 \%)$ & \multirow[t]{3}{*}{0.010} \\
\hline Not married & $12(5.7 \%)$ & $8(3.8 \%)$ & $5(2.4 \%)$ & $25(4.0 \%)$ & \\
\hline \multicolumn{5}{|l|}{ Number of pregnancies } & \\
\hline 1 & $54(25.7 \%)$ & $47(22.4 \%)$ & $32(15.2 \%)$ & $133(21.1 \%)$ & \\
\hline 2 & $42(20.0 \%)$ & $51(24.3 \%)$ & $46(21.9 \%)$ & $139(22.1 \%)$ & \\
\hline 3 & $41(19.5 \%)$ & $39(18.6 \%)$ & $49(23.3 \%)$ & $129(20.5 \%)$ & \\
\hline 4 & $27(12.9 \%)$ & $23(11.0 \%)$ & $21(10.0 \%)$ & $71(11.3 \%)$ & \\
\hline 5 & $23(11.0 \%)$ & $20(9.5 \%)$ & $20(9.5 \%)$ & $63(10.0 \%)$ & \\
\hline More than 5 & $23(11.0 \%)$ & $30(14.3 \%)$ & $42(20.0 \%)$ & $95(15.1 \%)$ & \\
\hline $\begin{array}{l}\text { Mean number of pregnan- } \\
\text { cies (sd) }\end{array}$ & $2.96(1.6)$ & $3.03(1.7)$ & $3.37(1.7)$ & $3.12(1.7)$ & 0.036 \\
\hline \multicolumn{6}{|l|}{ Source of income* } \\
\hline Agriculture & $29(13.8 \%)$ & $40(19.0 \%)$ & $20(9.5 \%)$ & $89(14.1 \%)$ & 0.019 \\
\hline Business & $170(81.0 \%)$ & $115(54.8 \%)$ & $156(74.3 \%)$ & $441(70.0 \%)$ & $<0.001$ \\
\hline Office work & $16(7.7 \%)$ & $6(2.9 \%)$ & $4(1.9 \%)$ & $26(4.1 \%)$ & 0.007 \\
\hline Labourer & $56(26.7 \%)$ & $17(8.1 \%)$ & $39(18.6 \%)$ & $112(17.8 \%)$ & $<0.001$ \\
\hline Other & $1(0.5 \%)$ & $40(19.0 \%)$ & $0(0.0 \%)$ & $41(6.5 \%)$ & $<0.001$ \\
\hline
\end{tabular}

*- Multiple responses were permitted 


\section{Family Planning}

About $96 \%$ of respondents had heard about the existence of family planning methods. All the respondents from Ketu North indicated that they knew at least one family planning method. It was only in Ketu South that the source of knowledge of family planning methods included Traditional Birth Attendants (TBA) and Community Health Planning Services (CHPS) compounds. Almost all participants (99.1\%) from Ketu North knew where they could obtain family planning services. Current use of family planning was significantly higher in Ketu North with $31 \%$ of respondents using a modern method. Overall current use of modern methods among the participants was $17.8 \%$. The use of the male condom, contraceptive pills and periodic abstinence was significantly higher in KetuNorth compared to the other districts while the use of implants was highest in Ketu South. Four hundred and fifteen respondents (65.9\%) stated that they are likely to use family planning methods in the future with Ketu North recording the highest response of $76.7 \%$. Even though there was no significant difference the highest proportion of women who had ever experienced an unwanted pregnancy was from Ketu South (51.9\%).

When the participants who had ever used family planning methods were asked about who made the decision about family planning use, significantly more women from Ketu North said that the decision was made together with the husband (31.4\%).

Table 2 Knowledge and use of family planning (FP) methods by women in Keta Municipal, Ketu North and Ketu South in the Volta Region, Ghana

\begin{tabular}{|c|c|c|c|c|c|}
\hline & Keta Municipal & Ketu North & Ketu South & Total & p value \\
\hline Know at least on FP method & $189(90.0 \%)$ & $210(100.0 \%)$ & $203(96.7 \%)$ & $602(95.6 \%)$ & $<0.001$ \\
\hline Know where to obtain FP & $183(87.1 \%)$ & $208(99.1 \%)$ & $187(89.0 \%)$ & $578(91.7 \%)$ & $<0.001$ \\
\hline Ever used modern FP & $82(39.0 \%)$ & $131(62.4 \%)$ & $75(35.7 \%)$ & $288(45.7 \%)$ & $<0.001$ \\
\hline Current use of modern FP & $22(10.5 \%)$ & $65(31.0 \%)$ & $26(12.4 \%)$ & $113(17.8 \%)$ & $<0.001$ \\
\hline Will use modern FP in future & $152(72.4 \%)$ & $161(76.7 \%)$ & $102(48.6 \%)$ & $415(65.9 \%)$ & $<0.001$ \\
\hline Has had an unwanted pregnancy in the past & $87(41.4 \%)$ & $89(42.4 \%)$ & $109(51.9 \%)$ & $285(45.2 \%)$ & $<0.001$ \\
\hline \multicolumn{6}{|l|}{ Decision making about FP } \\
\hline Woman herself & $41(50.0 \%)$ & $31(23.7 \%)$ & $37(49.3 \%)$ & $109(37.8 \%)$ & \multirow[t]{4}{*}{$<0.001$} \\
\hline Husband & $2(2.4 \%)$ & $29(22.1 \%)$ & $4(5.3 \%)$ & $35(12.2 \%)$ & \\
\hline Woman and husband & $33(40.2 \%)$ & $66(50.4 \%)$ & $34(45.4 \%)$ & $133(46.2 \%)$ & \\
\hline Other & $6(7.4 \%)$ & $5(3.8 \%)$ & $0(0.0 \%)$ & $11(3.8 \%)$ & \\
\hline
\end{tabular}

\section{Maternal Health}

About $94 \%$ of respondents attended antenatal clinic (ANC) during their most recent pregnancy. The highest recorded ANC attendance was $98.1 \%$ for Keta Municipal. However women from Ketu South had significantly more visits compared to the other two districts. The quality of antenatal care was much better in Ketu North where significantly higher proportions of women were informed about danger signs in pregnancy, told where to go when danger signs occurred and were tested for $\mathrm{Hu}-$ man Immunodeficiency Virus (HIV). Correct knowledge of the danger signs of pregnancy was also highest (68.8\%) among attendants in Ketu North.

Delivery in a health facility was highest in Keta Municipal $(62.3 \%)$ with overall delivery in a health facility being $57.6 \%$. Delivery by a skilled birth attendant (SBA) was also highest in Keta Municipal (61.9\%) while overall SBA coverage was (57.5\%).

\section{Postnatal care}

Seventy two per cent of women reported that they had a health worker check on them after the delivery of their last baby. Ketu North reported a significantly higher proportion of women who had a postnatal checkup $(86.2 \%)$ and $85.1 \%$ of these women in Ketu North were seen by a midwife. Eighty five per cent of these first postnatal check-ups took place within two days after delivery with majority occurring in the government hospitals (36.4\%). Significantly more women (95.6\%) from Ketu North received Vitamin A tablets after delivery.

Ninety per cent of the women in the study sample breastfed their last baby with $66 \%$ of them starting the breastfeeding immediately after delivery.

\section{Abortion and abortion services}

Table 5 shows us that even though significantly more women in Ketu North knew about abortion services, those of them who had used abortion services in the year preceding the survey had these abortion performed at home. 
Table 3 Use of Antenatal and delivery services in Keta Municipal, Ketu North and Ketu South in the Volta Region, Ghana

\begin{tabular}{|c|c|c|c|c|c|}
\hline Item & Keta Municipal & Ketu North & Ketu South & Total & p value \\
\hline Use of antenatal services & $206(98.1 \%)$ & $199(94.8 \%)$ & $192(91.4 \%)$ & $597(94.8 \%)$ & 0.009 \\
\hline $\begin{array}{l}\text { Informed about danger signs of pregnancy at ante- } \\
\text { natal clinic }\end{array}$ & $154(74.8 \%)$ & $191(96.0 \%)$ & $155(80.7 \%)$ & $500(83.8 \%)$ & $<0.001$ \\
\hline $\begin{array}{l}\text { Told at antenatal clinic where to go in event of } \\
\text { danger signs occurring }\end{array}$ & $151(98.1 \%)$ & $190(99.5 \%)$ & $148(95.4 \%)$ & $489(97.8 \%)$ & $<0.001$ \\
\hline $\begin{array}{l}\text { Correct knowledge of danger signs of pregnancy } \\
\text { by antenatal care attendants }\end{array}$ & $2(1.0 \%)$ & $137(68.8 \%)$ & $2(1.0 \%)$ & $141(23.6 \%)$ & $<0.001$ \\
\hline Had HIV test performed at antenatal clinic & $132(64.1 \%)$ & $186(93.5 \%)$ & $160(83.3 \%)$ & $478(80.1 \%)$ & $<0.001$ \\
\hline Received iron tablets at antenatal clinic & $203(98.5 \%)$ & $199(100.0 \%)$ & $181(94.3 \%)$ & $583(97.7 \%)$ & $<0.001$ \\
\hline $\begin{array}{l}\text { Received SP for intermittent preventive treatment } \\
\text { of malaria at antenatal clinic }\end{array}$ & $197(95.6 \%)$ & $196(98.5 \%)$ & $172(89.6 \%)$ & $565(94.6 \%)$ & $<0.001$ \\
\hline Delivered in a health facility & $131(62.3 \%)$ & $114(54.2 \%)$ & $118(56.1 \%)$ & $363(57.6 \%)$ & $<0.001$ \\
\hline Delivered by a Skilled Birth Attendant & $130(61.9 \%)$ & $114(54.2 \%)$ & $118(56.1 \%)$ & $362(57.5 \%)$ & $<0.001$ \\
\hline
\end{tabular}

Table 4: Postnatal care among women at Keta Municpal, Ketu North and Ketu South in the Volta Region, Ghana

\begin{tabular}{|c|c|c|c|c|c|}
\hline Item & Keta Municipal & Ketu North & Ketu South & Total & $\mathrm{p}$ value \\
\hline Postnatal care received & $144(68.5 \%)$ & $181(86.2 \%)$ & $128(60.9 \%)$ & $453(71.9 \%)$ & $<0.001$ \\
\hline Postnatal care received within two days of delivery & $130(90.3 \%)$ & $147(81.2 \%)$ & $106(82.8 \%)$ & $383(84.6 \%)$ & $<0.001$ \\
\hline \multicolumn{6}{|l|}{ Place of postnatal check-up } \\
\hline Government hospital & $86(59.7 \%)$ & $23(12.7 \%)$ & $56(43.8 \%)$ & $165(36.4 \%)$ & $<0.01$ \\
\hline Health centre & $41(28.5 \%)$ & $64(35.4 \%)$ & $36(28.1 \%)$ & $141(31.1 \%)$ & \\
\hline Private/Mission Hospital & $11(7.6 \%)$ & $88(48.6 \%)$ & $18(14.1 \%)$ & $117(25.8 \%)$ & \\
\hline CHPS compound & $1(0.7 \%)$ & $4(2.2 \%)$ & $7(5.5 \%)$ & $12(2.7 \%)$ & \\
\hline Private clinic & $2(1.4 \%)$ & $0(0.0 \%)$ & $10(7.8 \%)$ & $12(2.7 \%)$ & \\
\hline Polyclinic & $3(2.1 \%)$ & $2(1.1 \%)$ & $0(0.0 \%)$ & $5(1.1 \%)$ & \\
\hline Home/TBA & $0(0.0 \%)$ & $0(0.0 \%)$ & $1(0.9 \%)$ & $1(0.2 \%)$ & \\
\hline \multicolumn{6}{|l|}{ Provider of postnatal care } \\
\hline Midwife/Nurse/ CHO & $126(87.5 \%)$ & $154(85.1 \%)$ & $115(89.8 \%)$ & $395(87.2 \%)$ & $<0.001$ \\
\hline Doctor & $18(12.5 \%$ & $27(14.9 \%)$ & $13(10.2 \%)$ & $58(12.8 \%)$ & \\
\hline Received Vitamin A at delivery & $106(73.6 \%)$ & $173(95.6 \%)$ & $77(60.2 \%)$ & $356(78.6 \%)$ & $<0.001$ \\
\hline
\end{tabular}

Table 5 Knowledge and use of abortion services among women in Keta Municipal, Ketu North and Ketu South of the Volta Region, Ghana

\begin{tabular}{|c|c|c|c|c|c|}
\hline Item & Keta Municipal & Ketu North & Ketu South & Total & p value \\
\hline Know about existence of abortion services & $103(49.0 \%)$ & $184(87.6 \%)$ & $129(61.4 \%)$ & $416(66.0 \%)$ & $<0.001$ \\
\hline Used abortion services in the year preceding survey & $3(1.4 \%)$ & $24(11.4 \%)$ & $19(14.7 \%)$ & $46(7.3 \%)$ & $<0.001$ \\
\hline \multicolumn{6}{|l|}{ Source of abortion services } \\
\hline Home & $1(33.3 \%)$ & $13(54.2 \%)$ & $3(15.8 \%)$ & $17(37.0 \%)$ & $<0.001$ \\
\hline Health Facility & $1(33.3 \%)$ & $11(45.8 \%)$ & $8(42.1 \%)$ & $20(43.5 \%)$ & \\
\hline Other & $1(33.3 \%)$ & $0(0.0 \%)$ & $8(42.1 \%$ & $9(19.5 \%)$ & \\
\hline
\end{tabular}

\section{DISCUSSION}

This survey was conducted in three districts in the Volta Region which are not very much different in background characteristics. Despite the similarities in background characteristics there were significant differences in the maternal and reproductive health indicators. The main difference in background characteristics is related to economic activity. Ketu North district which had better health indicators also had relatively more people in the high economic level categories. This goes to show how much economic potential contributes to health status as has been shown in a number of studies performed in the country. ${ }^{4,5,6}$
This is the type of disparity that the introduction of the National Health Insurance Scheme (NHIS) in Ghana seeks to address.

The high level of knowledge of family planning methods seen in this survey is the same as has been shown in different family planning studies in the country ${ }^{4,8}$. The overall modern contraceptive method prevalence rate in this sample is higher than that recorded for the Volta Region in the Ghana Demographic and Health Survey and also higher than the overall rate for Ghana. ${ }^{9}$ 
This raises questions about whether these three districts have better family planning indicators than the rest of the region and also about the representativeness of the sample. The fact that over $60 \%$ of respondents intend to either start or continue using modern contraceptive methods in the future shows that with effective education and good counselling, contraceptive use in these districts can be raised even further. This study highlights the role of men in family planning us by their spouses. The highest level of male involvement in the decision to use family planning methods was seen in Ketu North which recorded the highest contraceptive prevalence rate among the three districts. Male involvement in family planning is very crucial especially in places such as Ghana where men continue to play a major leadership role in families and so exert a great influence over the choices made by women. ${ }^{10,11}$

The high use of antenatal services seen in this survey also mirrors the national situation. ${ }^{4,9}$ The improved health indicators in Ketu North could also be attributed to the quality of services delivered by the reproductive and maternal health workers. Ketu North stood out among all the districts with the high proportion of women who were informed about danger signs in pregnancy and what to do when these danger signs occur. Objective assessment of women's knowledge about danger signs confirmed this finding. Health workers play a major role in the improvement of health status even though it is well accepted that households and communities are also very crucial to improving health. The quality of maternal health services are generally better in Ketu North, suggesting that the good health indicators in the district are in part due to the work of the health workers. Despite these good health services, Ketu North showed the lowest coverage of births by skilled birth attendants. The reason for this discrepancy was not clear from the data obtained in the survey. There is the need to explore issues relating to ease of access of health facilities for delivery in Ketu North.

Abortion has been shown to be a health area with much controversy and stigma. Ghana has a fairly liberal abortion law, which is unknown to most of the general public and even medical practitioners., ${ }^{9,12}$ The stigma associated with the use of abortion services prevents women from patronizing the service even when they are rendered by a health facility. Despite the fairly high knowledge about abortion services in health facilities very few women have used the service. The stigma associated with the use of abortion services has been shown to lead to high rates of unsafe abortions with the attendant risk of resultant mortality. ${ }^{13,14,15}$
The results of this study bring out the need for effective family planning education and counselling in the districts. Interventions to improve male knowledge and male involvement in family planning is also needed. The interventions designed for these districts need to address the use of skilled birth attendants for delivery. There is also the need to work with health workers to improve the quality of maternal health care.

The maternal health outcomes that were studied are greatly influenced by personal, social and health system factors which were not all possible to measure. These confounding factors are a possible limitation on our explanations of the study findings.

\section{CONCLUSION}

Even though maternal mortality in Ghana is gradually decreasing, there are still a large number of mothers are faced with morbidity and mortality most of which are preventable. There is also a big gap between the current state of affairs and the target of Millennium Development Goal 5 in Ghana. This study was conducted to assess the state of maternal health care in three districts in the Volta Region and identify possible reasons for variations in maternal health care indicators among the districts. We obtained almost similar results in all the three target districts with utilization of family planning methods being low. Even though many of the antenatal care quality indicators measured showed greater than $50 \%$ coverage, the teaching about danger signs in pregnancy at antenatal clinics in Keta Municipal and Ketu South was clearly not very effective. This observed gap in antenatal care should be urgently addressed through training of the health care workers in these two districts on health communication about danger signs in pregnancy. Institutional delivery and rate of delivery conducted by Skilled Birth Attendants are much lower than the MDG 5 targets.

Based on the study findings, interventions to improve maternal health in these three districts should be focused on training of the health care workers in Keta Municipal and Ketu South on health communication about danger signs in pregnancy and increasing the contraceptive prevalence and institutional delivery rates in all three districts.

\section{REFERENCES}

1. World Health Organization, UNICEF, UNFPA, World Bank. Trends in maternal mortality: 1990 to 2010. Geneva: World Health Organization.2012

2. Osei I, Hodgson A, Adams F, Takrama W, Nam EW. Improving maternal and Child Health in the 
Volta Region. Accra: Ministry of Health(Ghana) and KOICA(Korea), 2013.

3. Twumasi PA.Medical Systems in Ghana-A study in Medical Sociology. Accra: Ghana Publishing Corporation, 2005:86

4. Ghana Statistical Service. Ghana Multiple Indicator Cluster Survey with an enhanced malaria module and biomarker 2011, Final Report. Accra: GSS, 2012

5. Ghana Statistical Service. 2010 Population and housing census. Summary report of final results. Accra:GSS, 2012

6. Hill AG, Darko R, Seffah JD, Adanu RMK, Anarfi JK, Duda RB. Health of urban Ghanaian women as identified by the Women's Health Study of Accra. Int J Gynecol Obstetrics 2007; 99(2):150-6

7. Henderson RH, Sundaresen T. Cluster sampling to assess immunization coverage: a review of experiences with a simplified sampling method. Bull World Health Organ 1982;60(2):253-60

8. Adanu RMK, Seffah JD, Hill AG, Darko R, Duda RB, Anarfi JK. Contraceptive Use by Women in Accra, Ghana: Results from the 2003 Accra Women's Health Survey. Afr J Reprod Health 2009; 13(1):123-33
9. Ghana Statistical Service, Ghana Health Service, ICF Macro. Ghana Demographic and Health Survey 2008. Accra:GSS, GHS and ICF Macro,2009

10. Adongo P.B, Phillips JF, Kajihara B, Fayorsey C, Debpuur C, Binka FN. 1997. Cultural factors constraining the introduction of family planning among the Kassena-Nankana of Northern Ghana. Soc Sci Med 1997; 45(12):1789-804

11. Nazzar A, Adongo PB, Binka FN, Phillips JF, Debpuur C.al., 1995. Developing a culturally appropriate family planning program for the Navrongo experiment. Stud FamPlann1995;26(6):307-24

12. Morhe ES, Morhe RA, Danso KA. Attitude of doctors towards establishing safe abortion units in Ghana. Int J GynaecolObstet 2007;98(1):70-4

13. Adanu RMK, Tweneboah E. Reasons, fears and emotions behind induced abortions in Accra, Ghana. Research Review 2004;20(2):1-9

14. Adanu RMK, Tweneboah E, Ntumy MN. Profile of women with abortion complications in Korle $\mathrm{Bu}$ teaching hospital, Accra. Trop Doct 2005;35(3):139-42

15. Konney TO, Danso KA, Odoi AT, Opare-Addo HS, Morhe S. Attitude of women with abortion-rlated complications toward provision of safe abortion services in Ghana. J Womens Health2009; 18(11):1863- 